\title{
Report
}

\section{Teaching and Learning Ecological Modeling over the Web: a Collaborative Approach}

\author{
$\underline{\text { Alexey Voinov }}^{I}$
}

ABSTRACT. A framework for web-based collaborative teaching has been created. This framework is implemented as an ecological modeling course (http://iee.umces.edu/AV/Simmod.html), but should be flexible enough to apply to other disciplines. I have developed a series of tools to facilitate interactive communication between students and instructors, and among students taking the course. The course content consists of reading materials that describe the theory of systems analysis and modeling, guidelines on how models can be built, and numerous examples and illustrations. The interactive part includes exercises that can be discussed with and evaluated by the instructor, and provides a means to mimic class discussions. To what extent this approach can replace conventional in-class tutoring has yet to be tested, but the preliminary applications show great promise. I offer this course format as a framework and a prototype for collaborative "open-source" approaches to education, in which the web provides the means to communicate knowledge and skills asynchronously between geographically dispersed educators and students.

\section{INTRODUCTION}

Although web tools have only recently been used for educational purposes, there is clearly increasing interest in such an application of the web. The number of sites related to education is vast and growing. Sites that offer educational opportunities fall into several main categories. To describe these categories, let us look at the educational process as a triad made up of the knowledge base, the instructor, and the student or class (Fig. 1). Traditionally, two main types of interactions have been involved. Human interactions are those that occur between individual humans and human aspects of the educational process; for example, students interact with the professor and with each other. Stiff interactions occur between humans and the media (books, databases, computer files, etc.) that store and maintain the knowledge base. Both kinds of interactions may vary in the level of reciprocity allowed or encouraged. Some instructors are extremely flexible, and can react readily to the character and needs of each student, but, with other instructors, students may have to adapt more. Similarly, there may be one-way or two-way interaction with the knowledge base, and even twoway communications may vary in their flexibility. Certain types of electronic media can be easily and rapidly updated, while print materials (books, journal articles) are usually filtered and delayed by the peer review process.

The educational process, then, is the interaction between the student and the knowledge base, mediated in some way by the instructor. In the archetypal lecture format, instructors are intermediaries between the knowledge base and the students. They wrap knowledge from the knowledge base in an appropriate format and deliver it to students. Students absorb information either from the instructor or directly from the knowledge base, in which case the instructor guides or supervises how the students learn. Students' direct access to the knowledge base varies, depending upon the educational format and the preferences of individual students and instructors.

Instructors may or may not participate in the creation of the shared knowledge base. Some play a more active role, being researchers themselves and contributing information to it. Others are primarily educators, and add little or nothing to it. However, instructors always contribute to their own individual knowledge bases, modifying them with the experience they gain, particularly with their knowledge of how people learn and how they may be helped in the educational process. In many cases, the latter knowledge is not shared and is likely to be lost. 
Fig. 1. The educational process as a triad made of the knowledge base, the instructor, and the student.

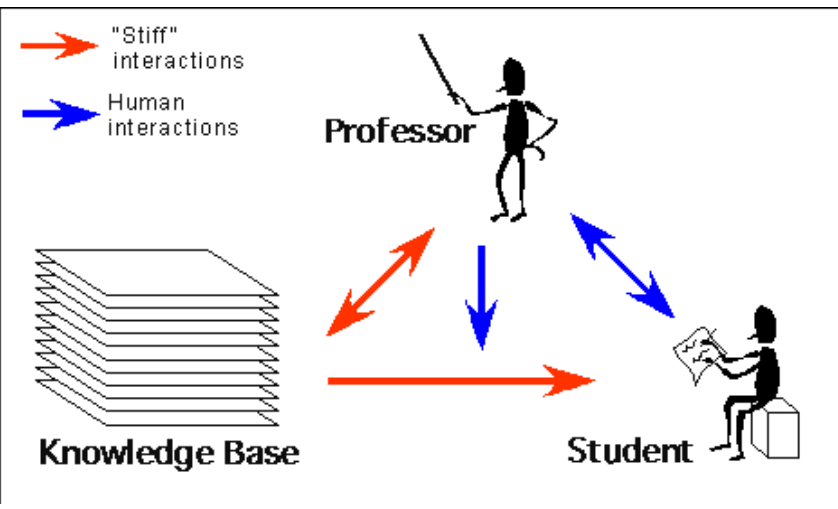

Fig. 1A. Introduction of web-based tools and applications to enhance the in-class education process.

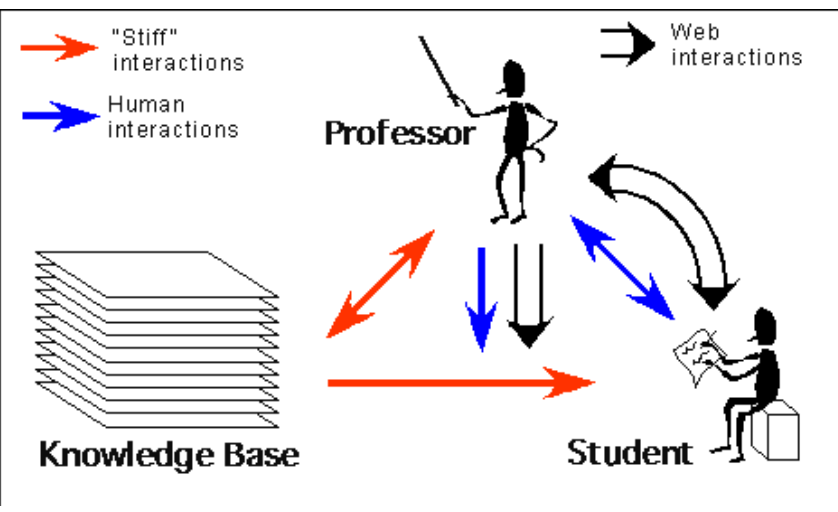

Fig. 1B. In distance learning, the human interactions are entirely replaced by the web, but most of the information is provided by non-web sources (textbooks, CDs, videos).

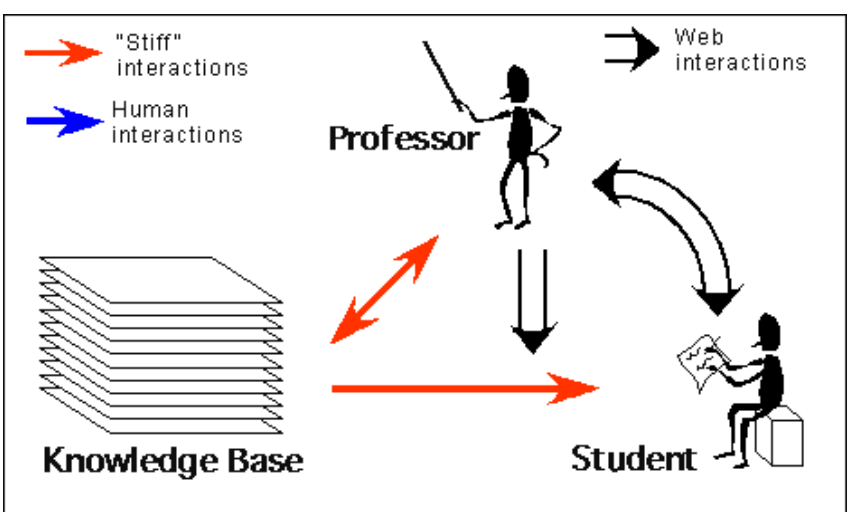

Fig. 1C. The web pages created by educators and researchers offer a lot of content, but are not designed for interaction with the instructor.

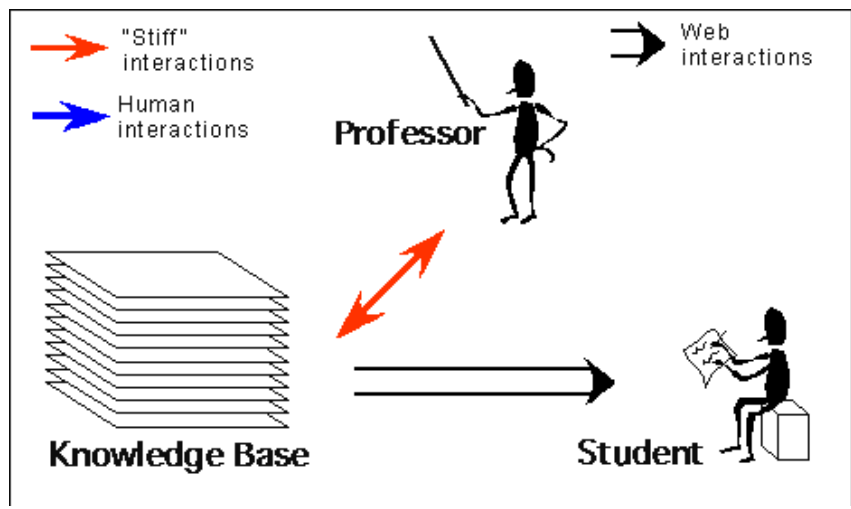

Fig. 1D. An interactive web course offers both the content and the interaction over the web. It also provides means for collaborative teaching, when several professors at different locations can teach the course with the help of advanced students.

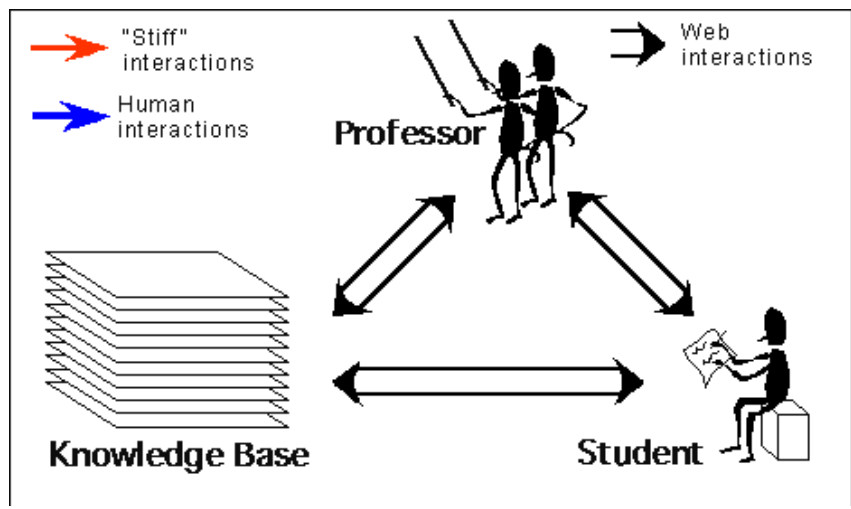

Web tools can be applied to all stages of the educational process. The web is used to facilitate the instructors' work in the classroom. Courses still meet in a conventional classroom environment and the instructor still teaches conventionally, but he/she employs the web for additional messaging and assignments (Fig. 1A). At present, most university professors probably already use the web in this form, or have considered it. They either post their syllabi on the web, or use it to complement or supplement the material they present in class. Some sophisticated commercial software is now available for these purposes (e.g., Blackboard, WebCT). In all of these approaches, however, the web part of the course is 
only an addendum to what the instructor offers in class. The web site is designed for that particular course and, in many cases, access is limited to class participants.

Another group of educational web sites has been developed to facilitate distance learning, replacing direct human interactions with web interactions (Fig. $1 \mathrm{~B}$; click on the figure caption). The course format is offered on the web, but most of the knowledge base resides in non-web sources (textbooks, videotapes, audiotapes, CDs), which are purchased separately and delivered by regular mail. Some examples of such institutional distance-learning web pages are the New Jersey Institute of Technology Division of Continuing Professional Education and the University of Maryland University College, and Instructional Systems Inc.

These types of distance-learning websites have been offered for over a decade already and at least one-third of American universities and colleges now offer webbased distance education (Schuhmann et al. 2000). The University of Phoenix was among the first accredited universities to provide college degree programs over the Internet, starting in 1989. It claims to be the "nation's leading online university," but there is now a good deal of competition among distance education programs of this kind. Because they tend to employ conventional marketing tools and mechanisms, it is hard to identify their relative benefits. For example, The University Alliance seems to provide almost the same scope of programs and also claims to be the nation's leading university. As with many other advertisements, each program strives to be the first, the best, the top, yet in essence the services and tools they offer look quite similar.

Educators and researchers have also developed their own web pages to use in their own courses or to create an alternative or addendum to mainstream publishing (e.g., The Economics Centre of the Learning and Teaching Support Network and RDN Virtual Training Suite). These pages present a lot of content, but are not designed for interaction with the instructor (Fig. 1C). They may include some interactive web applications to test progress, but they are usually limited to multiplechoice tests that do not need the instructor's participation. The web pages are in the public domain, their content is available for the search engines, and they are very useful for browsing the web for answers to particular questions. They also offer a wealth of information and examples for teachers. However, such courses usually offer no credit toward degrees or certificates.

The list of resources specifically for teaching ecology and environmental sciences is not long, but some excellent material is already available. For example, see the survey developed at the Central European University. In most cases, the web is still either auxiliary to traditional classroom communications, or a means to deliver distance-learning material. Rarely is it the sole source of both content (knowledge base) and teaching tools (interaction).

My ultimate goal in this endeavor was to build a course for students with access only to a computer hooked to the Internet. In this case, the web is used both to provide access to the knowledge base and to allow for interaction between the educator and the students (Fig.1D). The web also allows many instructors at different locations to participate in a collaborative teaching process. Through their joint efforts, these many teachers may evolve and keep the course in the public domain, promoting truly equal opportunity in education anywhere in the world. By constantly keeping the course available for asynchronous teaching, we can have overlapping generations of students involved at the same time, and may expect the more advanced students to help the beginners.

Because of my particular background and interests, the course developed is in simulation modeling in ecology and environmental sciences. The Internet offers a number of advantages to this course, but there is no reason why only this particular course may be taught in this way. Many other courses could be offered as well, with the same or slightly modified format. Potentially, any course that requires no extensive experimental laboratory work or face-to-face communication should be made available by these means.

In fact, the modeling course is certainly not the easiest one to teach in an asynchronous, distant way. It requires a lot of interaction that includes graphics and formulas, and assumes considerable discussion and student-professor exchange. However, at this time, with no special advertising, the course pages have seen more than 300 visitors from around the world (in addition to my own students). No students have yet fulfilled all course requirements and "graduated," but four students are currently involved and are making slow progress. The web course also has been used 
successfully to teach two extensive short courses in the Chulalongkorn University (Bangkok) M.Sc. Program in Environmental and Natural Resource Economics, with about 30 students participating in each. That case was not a "clean" test because there were also class meetings and face-to-face interaction. However, all exercises were delivered, submitted, checked, discussed, and graded entirely over the web.

Parts of the Modeling web course have been also integrated into a course on Ecological Economics, offered as part of a short-course graduate workshop held in the Commonwealth of Dominica in June 2001. In this case, the web format was especially useful because students from 16 countries had the opportunity to gain background knowledge and skills before attending the workshop. Some 24 students in that short course used the reading materials from the course and five of them submitted exercises and participated in some discussions.

The accreditation problem has yet to be resolved. Credit-granting courses certainly draw more interest and attention. The Modeling web course has not been officially recognized by any university and offers no credit toward degrees or certificates. However, there is a certain advantage in keeping it that way because the course may thus remain in the public domain if supported by a community of educators who wish to collaborate in teaching and course development over the web under the open-source paradigm. Eventually, open-source collaborative education may become an alternative or extension to the standard university curriculum development and course hosting, in which courses are restricted to registered, paying students. Accreditation of such open-source courses may be based upon the respect they generate among the students and the instructor's peers, who may also serve as instructors contributing to the course.

\section{COURSE OVERVIEW}

The overall goal of the Modeling course is to show how simulation modeling can help in understanding systems and system dynamics. The art of modeling is more than piling up variables in an incomprehensible web of interactions and feedbacks, incorporating all available information into the simulation framework. More important is to identify the skeleton of the system, and to understand the few main driving factors, parameters, and processes. The real value of a model is to reveal these control factors and explain how the rest of the system components evolve around them. As C. S. Holling describes it, "if you cannot retain a handful of causes in your explanation, then your understanding is simplistic. If you require more than a handful of causes, then it is unnecessarily complex" (Holling 2000).

Many well-known simulation models (Forrester 1969, Meadows et al. 1972, Fitz et al. 1996) were not created to further our understanding of systems dynamics. They are too complex to truly reveal the underlying systems behavior (Berlinski 1978). We should rather consider them as part of the data-assembling process. Just like databases or spreadsheets, they are essential for collecting and preprocessing the data in a readable, consistent, and comprehensive format. By no means does this make them less useful or appropriate. We just need to remember that they are built in pursuit of a different goal. The power of simple models becomes evident when, by analyzing the model structure and performance, one can explain the controls and driving factors in the model and then relate this new understanding to the real system studied (Benbasat and Gass 2002). Examples of these simpler models are presented by Svirezhev and Logofet (1983), Voinov and Tonkikh (1987), Gurney and Nisbet (1998), Carpenter et al. (1999), and others.

In this course, I have focused mostly on simple models; however, some more complex models are also introduced. The course map is presented in Fig. 2. Because of the multidimensional structure of the web media, the course, unlike a book, does not have to evolve along a linear trajectory. There may be many side branches and jumps backward and forward. The first four modules give a general overview of modeling concepts and teach the techniques and methods of modeling. They are essential to understand the main modeling concepts, and students are advised to start from them. The other modules are examples and case studies. There is no specific sequence in which to study them, and the list of modules is easily expanded and updated. Exercises are embedded within the content of the modules. 
Fig. 2. The course map.

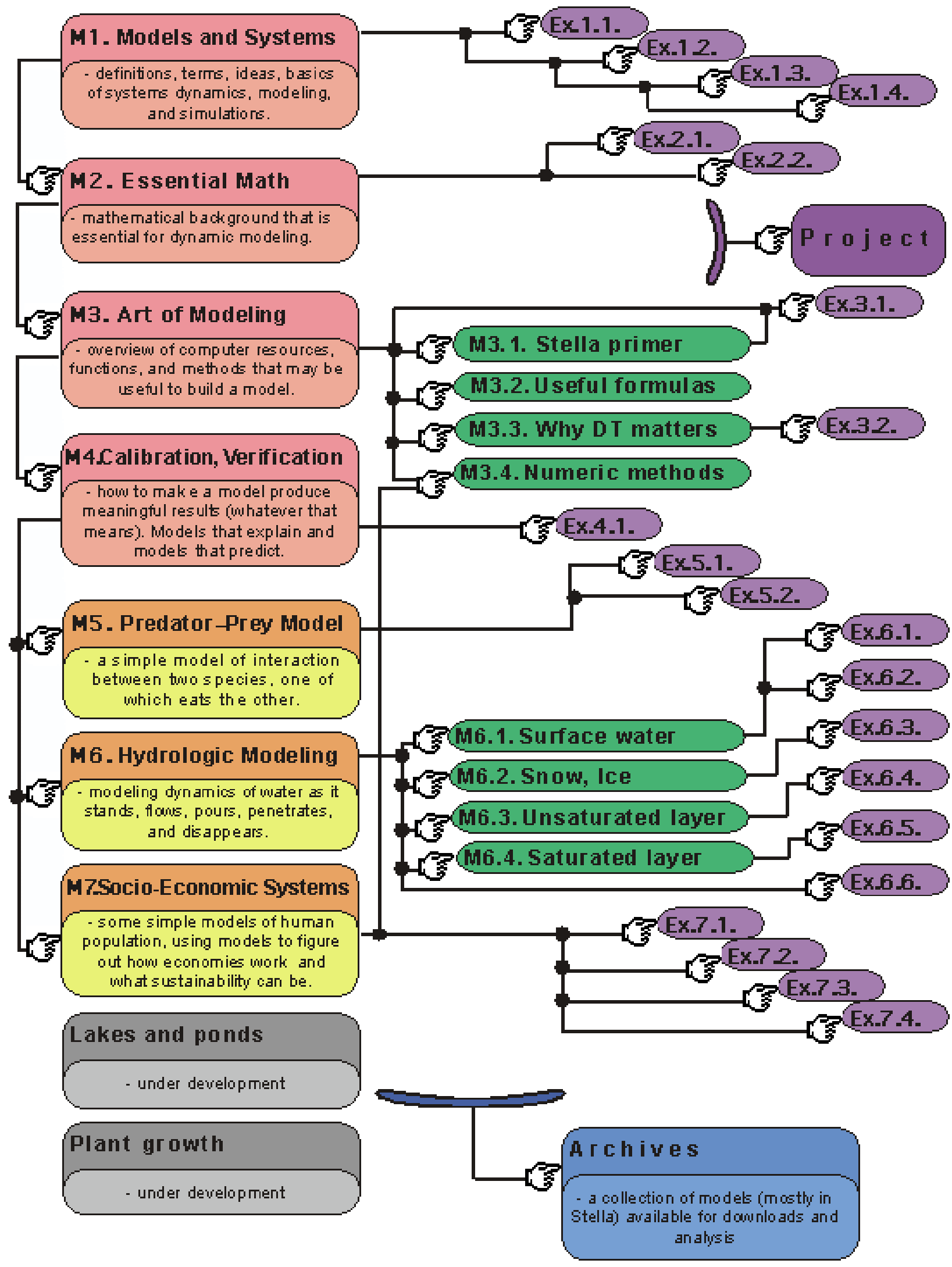


Quite early in the course students are invited to start working on their individual projects (Galindo-Leal 2001). We believe that modeling cannot be really taught, only learned, and that it is a skill that requires a lot of practice. Without going through the pitfalls and surprises of dynamic modeling, students cannot quite understand the process. Learning the skill must be a hands-on experience of all the major stages of modeling, from data acquisition and building conceptual models to formalizing and iteratively improving simulation models.

Throughout the course, we illustrate the importance of the four basic rules of dynamic modeling:

1. Keep it simple. The real value of models is in their simplified description of complex systems. If a model of a complex system also turns out to be a complex system with dynamics that are hard to analyze and interpret, it will be more useful as a data storage and processing tool, rather than for researching and understanding system dynamics. These are just different types of models.

2. Keep it running, keep testing it. It is easier to understand model behavior if complexity is added gradually and systematically. In analysis, we learn how models behave and how they may behave under different circumstances. If the model is correct, we may expect that the system will display similar behavior. Without model analysis much of the modeling is useless if our goal is better understanding of the system.

3. The modeling process is even more important than the result. The model that comes out of the modeling process can be a success or it can be a failure. It can be more useful, less useful, or entirely useless. As W. Deming describes it, "All models are wrong, some models are useful" (McCoy 1994). However, the process of building the model is always useful, because it always generates new knowledge about the system, its components, and interactions between them.

4. There is no such thing as useless data. Modeling is driven by the goals of the study and by the system under study. Therefore, whatever data we have about the system should be considered when modeling. Eventually the data may be left out of the model, as most data are. But that should be a conscious decision, based on research goals and chosen scales of time, space, structure, and precision.

Most of the demonstrations and exercises in the course were created using the STELLA ${ }^{\circledR}$ modeling package. STELLA offers many tools for dynamic modeling and is widely used, especially in academia. A free run-time version can be downloaded from the High Performance Systems web site. It should be enough to go through all the exercises and examples presented in the course. However, a fully functional version of STELLA would be essential to create the course project, which is the core of the studies. There is a growing choice of other similar packages nowadays, some of which exceed STELLA in a number of ways. For example, another modeling package, Madonna, developed at Berkeley, is also introduced in the course. Therefore, there is no requirement to use only STELLA. Many other software packages, or even straight programming, should be sufficient to fulfill the goals of the project.

Several types of interactive exercises are embedded in the course. Interaction between students and instructors is essential, and should be facilitated rather than inhibited or eliminated by web-based teaching. The exercises require answering questions or uploading models to the instructor. All student answers are stored in a database entry, called a "profile." The profile also contains all comments by instructor(s), and is used to grade the work.

Access to each student's profile is password-protected, and each student maintains only one profile. On the student side of the profile, text areas can be used to submit answers (Fig. 3). The professor side of the profile looks similar, but the right-hand boxes are open for comments. Once a grade is given, the student-side box becomes inactive and no more changes can be made (Ex. 01.01.02 has been already graded in Fig. 3). When all exercises for a module are graded, a URL to the Answers page is opened to the student, where a more detailed discussion of the results is available. Multiple-choice exercises are inserted into the profile and graded automatically, and require no action by the instructor. 
Fig. 3. Student side of the profile. All the answers to the exercises are registered in the profile and students can come back and edit their answers based on the instructor's comments. On the professor side of the profile, the professor inserts his comments and either grades the exercise or starts a discussion, providing an opportunity for improvement and better mutual understanding.

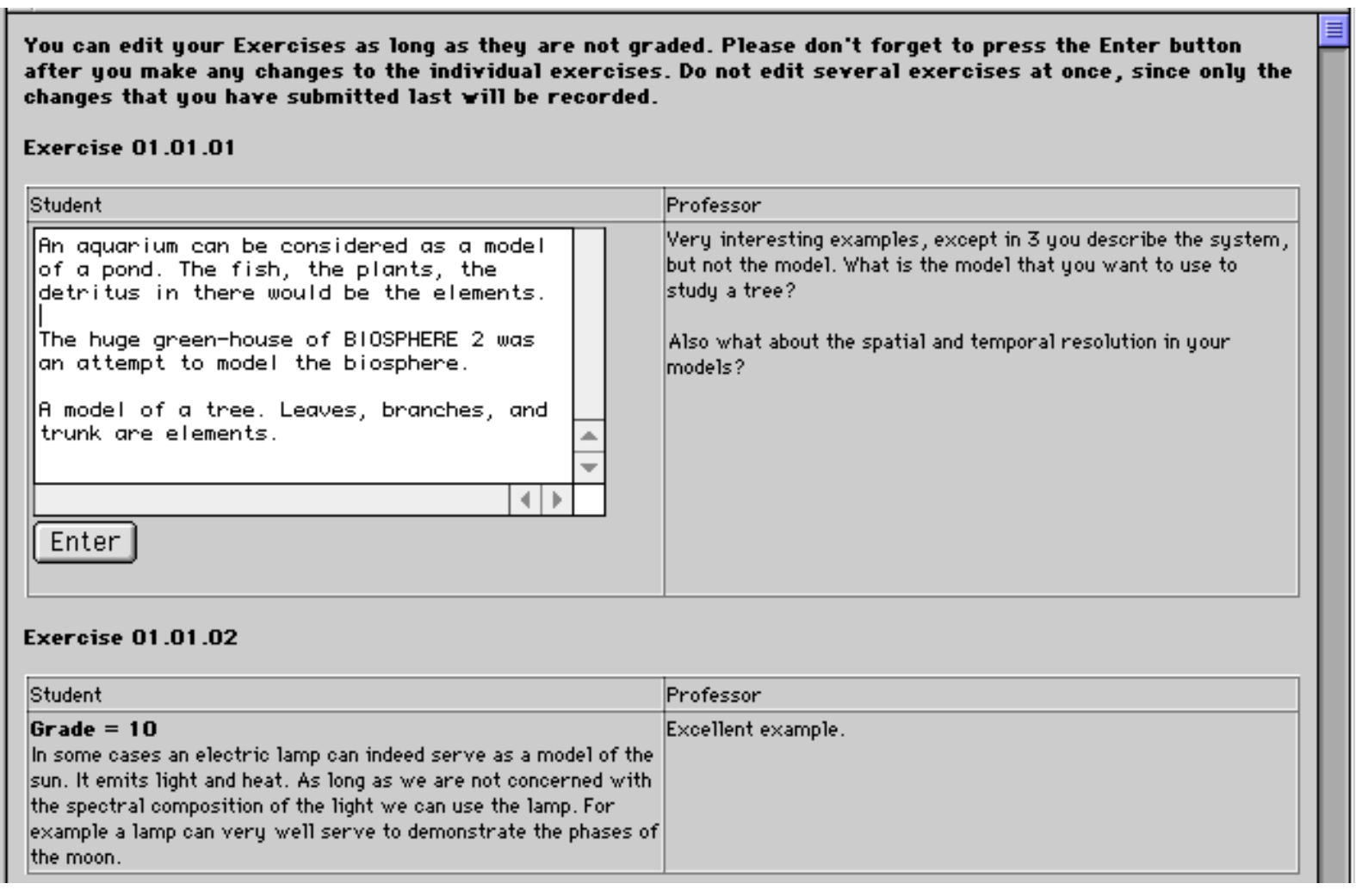

The project submissions also become part of the profile. They consist of two major components: the discussion box, which is similar to the exercises, and the Upload tool that opens an ftp box for transmitting student models to the instructor. Once the models have been reviewed and commented on by the instructor, they are sent back to the student(s) as e-mail attachments. Because I do not administer the web server used for the course, I do not at this time maintain outgoing ftp services for individual students.

Animation is another tool that is unavailable in a book format (although some books do come with CDs attached), but that is very useful to illustrate and explain dynamics of certain processes. For example, Fig. 4 illustrates the chaotic behavior of a dynamic model, which would be impossible to show in a standard static illustration. We can actually see how the trajectory loops in the phase plane, with the amplitude randomly changing. It would require a long series of graphs to present this in a print version, and the understanding that comes through direct visual experience of the effect would still be hard to match.
Fig. 4. Animation of the chaotic cycling observed in one of the models of the Population-Resource system. This type of dynamics would be hard to demonstrate in a standard static illustration. [see www.consecol.org/vol6/iss 1/art10/figure4.html]

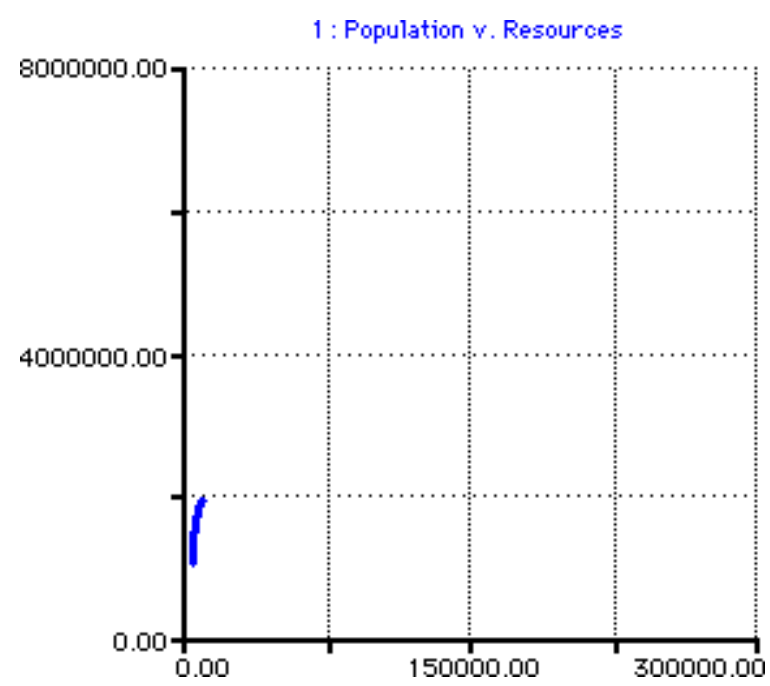


The reader is welcome to explore the course content at http://iee.umces.edu/AV/Simmod.html. The development of user-friendly modeling software, such as STELLA, has very much simplified the process of building models. However, this simplicity may be misleading. Most software advertising suggests that building a model has now become as simple as clicking a mouse. This is not so and can hardly ever be so, because modeling, even by students, will always remain primarily a research process that requires knowledge and understanding of the system to generate more knowledge and more understanding. By itself, simply dragging and dropping icons and connectors, drawing diagrams, or pulling together preexisting modules or building blocks hardly increases our understanding of particular systems and processes. Insight is required to guide model building and analysis is required to develop understanding. The available modeling systems are indeed very helpful to those who already know how to build models. They are also excellent tools to illustrate and support the overall modeling process, and can be very helpful for educational purposes. However, when used without an understanding of the processes and an awareness of the mathematical formalism involved, these tools may become deceptive distractions. This is one of the important messages that we try to deliver in this course presentation.

\section{WHAT NEXT?}

\section{Object-oriented teaching}

One major advantage of web tutorials is that new facts and findings can be incorporated almost as soon as they are announced or published. It takes years to publish or update a book, but only minutes to insert a new finding or a URL into an existing web structure. By the time readers of this paper examine the course, it will be different from what it is as I am writing about it because there are always new ideas and results to implement and present. The virtual class discussions provide additional material for the course. All this can easily become part of the course modules.

The web offers a hierarchical structure that allows immediate access to a variety of sources that are relevant to what is discussed at any place in the course. These links can point both to pages within the same course presentation or to entirely foreign locations. Instead of the linear structure of a book, where flashbacks and jump-forwards require flipping through pages and may be quite distracting, the web presents a multidimensional format that places the readers quickly into the right place. It is like the difference between an audiotape and a CD: you can jump from one song to another without waiting for the tape to rewind.

The flexibility and multidimensional structure of the web is essential for the modularity of course composition; the whole course can be assembled in modules mimicking the object-oriented approach used in programming. The goal is to have each module as a self-contained portion of information and activities, with clearly identified links backward and forward. For each part there will always be a link backward that explains it by placing it in a context and referring students to other relevant data and knowledge, and a link forward that enhances or extends the topic. As in object-oriented programming, modules formulated as objects can be used further to build new objects, inheriting certain features and adding new ones. On the other hand, certain components may hidden from users, particularly implementations of the course finetuned for specific groups, applications, and tasks. Certain links may be deactivated if the targeted audience is over- or underqualified to benefit from exposure to those course modules. In this way, it becomes easy to assemble new courses from these modular teaching objects to meet the requirements of different disciplines and various academic levels, especially as possible modules accumulate. This proliferation is a major benefit of collaborative instruction.

For example, we are currently experimenting with applications of modules from this modeling course in a high school course on watershed management and in a graduate-level course in ecological economics. It took only a couple of hours to assemble an entirely new course presentation for another short-course workshop that took place in Brazil in January 2002. In this case, a number of modules on ecological economics (created by Josh Farley in compliance with the web-course conventions) were merged with several modules from the modeling course, creating an entirely new presentation (see http://iee.umces.edu/AV/EDU/EE ).

\section{Collaborative teaching}

Another opportunity opened by web-based education can best be described as distributed open-source teaching; it mimics the open-source concept that stems from the hacker culture. The idea of free, shared software source code is probably best known in 
connection with the Linux operating system. After Linus Torvalds developed its core and released it to software programmers worldwide, Linux became a product of the joint efforts of many people, who contributed code, bug reports, fixes, enhancements, applications, and plug-ins. The idea gained momentum in 1998 when Netscape released the source code of its Navigator, the popular Internet browser program. That is when the term "open source" was coined and when the open-source concept was legally defined.

A crucial aspect of open-source licenses is that they allow modifications and derived works, but they must also be distributed under the same terms as the license of the original software. Therefore, unlike simply free code that could be borrowed and then used in copyrighted commercial distributions, the open-source definition and licensing effectively ensures that the derivatives stay in the open-source domain, extending and enhancing it. Largely because of this feature, the open-source community grew very quickly.

To organize this growing community, the Open Source Development Network (OSDN) was created. Like many previous open-source spin-offs, it is based on the Internet, providing teams of programmers distributed around the world with a virtual workspace where they can discuss ideas, progress, and bugs, and share updates and new releases. The open-source paradigm has become the only viable alternative to copyrighted, closed, and restricted corporate software.

The success of the open-source approach in software development has stimulated scientific researchers to start considering similar shared, open approaches to scientific research. This research is based on Internet communications and can be conducted simultaneously at numerous institutions working on parts of joint research projects (Schweik and Grove 2000). Projects are open to new researchers, and results and credit are shared among all the participants.

The open-source paradigm may also be used to advance education. Web-based courses such as the one described here could serve as a core for joint efforts of many researchers, programmers, educators, and students. Researchers could describe the findings that are appropriate for the course theme. Educators could organize the modules in subsets and sequences that would best match the requirements of particular programs and curricula, and develop ways to use the tools more effectively. Programmers could contribute software tools for visualization, interpretation, and communication. Students would test the materials and contribute their feedback and questions, which are essential to improve both content and form.

Students can learn much from textbooks and recorded sources. However, a good teacher is essential to facilitate and expedite the learning process. Borrowing from the open-source experience of material development, we can also envision a community of educators who would participate in teaching a webbased course, logging on to the virtual classroom to contribute to the discussions with students, to answer their questions, and to grade their exercises. In this case, the talents of the best teachers can be made available to the widest possible audience of students. With a sufficient number of qualified volunteers involved, this kind of education could become a free alternative to increasingly expensive university education. In compliance with the open-source definition, students educated for free would in turn be expected to contribute in the future to this kind of free virtual education, further enhancing the community of educators.

A web page to organize the community of volunteers interested in teaching applied simulation modeling is currently under development. However, it is easy to envisage an Open Network for Education (ONE) in a variety of disciplines, set up in a way similar to the OSDN, to promote and organize free open-source education.

\section{CONCLUSIONS}

\author{
All theory, my friend, is gray, \\ But green is life's glad golden tree. \\ J. W. Goethe (Translated by P. Wayne)
}

The purpose of this presentation is twofold. On one hand, it introduces a web course in dynamic simulation modeling and some of the basic principles that the course assumes. On the other, it offers a vision of an alternative type of education based on collaborative efforts of educators around the world, linked by the Internet.

The web offers some useful tools to illustrate the concepts of dynamic modeling and to allow hands-on experience in modeling. We have seen how animations and interactive sharing of model code can easily be made available with web applications. Most likely we will discover other advantages of the web approach as courses in other subjects are developed, or at other 
levels. In all cases, one major advantage of the web approach to education is that we create a living system. A book usually takes at least a couple of years to write and publish, and at least another couple of years before changes can be made and the book reprinted. The book comes as a given; it allows little interaction with readers, who can either accept it or not, but who cannot change it. Classroom teachers are there mostly to compensate for this stiffness of the textbook, its lack of interactivity. They add their own experience and personality to the textbook, and draw from alternative sources of information. They can finetune their courses to the needs of particular classes or students. However, it requires truly devoted teachers to keep up the standards no matter how many times they have already offered their courses.

A web course is first of all a book, but a living book that is constantly updated. Interesting discussions or questions that arise in class can be immediately inserted into the body of the course and become part of the future readings. Nothing is lost; everything is recorded and is available for reuse. Also, as science develops, the newest and hottest findings can be either quickly reflected on the course pages or referenced from them.

Clearly, the pages currently available only mark the start of course development, and are mostly a product of volunteer work by one individual. I imagine this course as a living system that can grow on its own as it matures and pulls in additional knowledge and experience, and additional volunteers, all generated from its growth. The online community of teachers has yet to be created and the many other pages and links are yet to be developed. At this time, it is a vision, a format, and a demonstration of what educators and scientists can achieve in the future through concerted, coordinated efforts. However, it is a working demonstration that is already useful and has already produced results. There is no doubt that face-to-face education offered by the best teacher with the best textbook and best teaching materials will always be better than any distance-learning experience. The question is whether all students can get the best teacher, the best book, and have time and money to afford this kind of education. The described collaborative web-based approach may be a practical alternative for many such students, and it may be much to the advantage of all students to be exposed to and acquainted with their potential future colleagues during the learning process.
In reality, it is always difficult to predict in advance how a technology will be used and what form that use will eventually assume in society. Could anyone have predicted the success of the Open-Source Development Network in advance? The ultimate driver of this idea is user demand and how it develops. What is the incentive for instructors to participate in such a format? Are software programmers unique in their willingness to share their achievements with the rest of the world with no apparent direct material return? Would scientists and educators also be willing to share their knowledge and skills with others, especially with less advantaged ones who may not be able to afford the cost of college education? One may argue that shared software code is often developed as part of specific projects funded by grants and, therefore, a priori belongs to the public domain. However, many research projects also carry funds for educational purposes (student tuition, etc.). Should we assume that the results of such educational efforts should also belong to the public domain? Would a student who received his education for free, on taxpayers' money, be expected to share some of his education, also for free, with the rest of society? Clearly these questions are not simple to answer; however, the collaborative educational framework can offer a useful means for sharing education.

Hundreds and thousands of people participate in numerous discussion lists, contributing thousands of man-hours to share their experience, knowledge, and advice. Hardly any reasonable questions sent to appropriate mail lists remain unanswered. There always seems to be somebody willing to help, to share. Would there be also interest in a more structured exchange of knowledge that could be channeled into an educational format, potentially granting credit and degrees? Would it be possible to have a critical mass of students involved in taking the course at any one time? Would they be willing to keep in touch with their successors to share their newly achieved skills and knowledge? At this point these questions remain open. Clearly, the ultimate test of the ONE idea will be whether it catches on in the virtual domain.

Responses to this article can be read online at: http://www.consecol.org/vol6/iss1/art10/responses/index.html.

\section{Acknowledgments:}

My thanks are due to my wife Helena and sons Anton and Ivan, who forgive me the many hours taken from them and 
spent here. I thank Court Smith and Josh Farley for their encouragement and useful comments. I also thank Robe rt Costanza for the valuable experience I obtained while coteaching a modeling course at the University of Maryland. The web space and computer resources wer e provided by the University of Maryland Institute for Ecological Economics. Tha nks also go to anonymous reviewers of the paper for helpful comments and encourage ment. My very special thanks are to Lee Gass for many stimulating ideas and tedious editing of the manuscript.

\section{LITERATURE CITED}

Benbasat, J. A., and C. L. Gass. 2002. Reflections on integration, interaction, and community: the Science One program and beyond. Conservation Ecology 5(2):26. [Online, URL: http://www.consecol.org/vol5/iss2/art26 ]

Berlinski, D. 1978. On systems analysis. An essay concerning the limitations of some mathematical methods in the social, political, and biological sciences. The MIT Press, Cambridge, Massachussetts, USA.

Carpenter, S., W. Brock, and P. Hanson. 1999. Ecological and social dynamics in simple models of ecosystem management. Conservation Ecology 3(2):4. [Online, URL: http://www.consecol.org/vol3/iss2/art4 ]

Fitz, H. C., E. DeBellevue, R. Costanza, R. Boumans, T. Maxwell, L. Wainger, and F. Sklar. 1996. Development of a general ecosystem model for a range of scales and ecosystems. Ecological Modelling 88(1/3):263-295.

Forrester, J. W. 1969. Urban dynamics. The MIT Press, Cambridge, Massachussetts, USA.

Galindo-Leal, C. 2001. Design and analysis of conservation projects in Latin America: an integrative approach to training. Conservation Ecology 5(2):16. [Online, URL: http://www.consecol.org/vol5/iss2/art16 ]

Gurney, W. S. C., and R. M. Nisbet. 1998. Ecological dynamics. Oxford University Press, New York, New York, USA.

Holling, C. S. 2000. Theories for sustainable futures. Conservation Ecology 4(2):7. [Online, URL: http://www.consecol.org/vol4/iss2/art7 ]

McCoy, R. 1994. The best of Deming. Statistical Process Control Press, Knoxville, Tennessee, USA.

Meadows, D. H., D. L. Meadows, J. Randers, and W. W. Behrens III. 1972. The limits to growth. Universe Books, New York, New York, USA.

Schuhmann, R. A., R. M. Cawley, R. T. Green, and A. Schenker. 2000. The MPA and distance education: a story as a tool of engagement. Public Administration and Management: An Interactive Journal 5:N4. [Online, URL: http://www.pamij.com/5 $4 / 5$ 4 4 _ 3 mpa.html ]

Schweik, C. M., and J. M. Grove. 2000. Fostering opensource research via a world wide web system. Public Administration and Management: An Interactive Journal 5:N4.

[Online,

URL:

http://www.pamij.com/5 4/5 4 __ 2 opensource.html ]

Svirezhev, Y. M. and D. O. Logofet. 1983. Stability of biological communities. Mir, Moscow, Russia.

Voinov, A. A., and A. P. Tonkikh. 1987. Qualitative model of eutrophication in macrophyte lakes. Ecological Modelling 35:211-226. 